\title{
Pulmonary function in firefighters: acute changes in ventilatory capacity and their correlates*
}

\author{
A. W. MUSK $\uparrow$, T. J. SMith, J. M. Peters, AND E. Mclaughlin \\ From the Occupational Health Program, Harvard School of Public Health, 665 Huntington Avenue \\ Boston, MA 02115, USA
}

\begin{abstract}
A group of 39 firefighters was examined during routine firefighting duty. Following smoke exposure the average decrease in one-second forced expiratory volume $\left(\mathrm{FEV}_{1.0}\right)$ was 0.05 litre (137 observations). This decline in $\mathrm{FEV}_{\mathbf{1 . 0}}$ was related to the severity of smoke exposure as estimated by the firefighter and to the measured particulate concentration of the smoke to which he was exposed. Decreases in $\mathrm{FEV}_{1.0}$ in excess of $0 \cdot 10$ litre were recorded in $30 \%$ of observations. Changes in $\mathrm{FEV}_{1.0}$ resulting from a second exposure to smoke on the same tour of duty were greater when smoke exposure at the previous fire was heavy. The repeated episodes of irritation of the bronchial tree that have been documented in this investigation may explain the origin of the previously observed chronic effect of firefighting on respiratory symptoms and pulmonary function.
\end{abstract}

Acute changes in pulmonary function have been shown to occur as a result of firefighting. These changes are greater if the firefighters are exposed to known respiratory irritants (Thomas, 1971). However, data on the frequency and severity of such changes and on the specific physical or chemical nature of the exposures responsible do not exist. Under experimental conditions materials such as nitrogen oxides (Olsen et al., 1930; Nichols, 1930), hydrogen chloride (Dufore, 1963; Gross et al., 1969) and hydrogen cyanide (Olsen et al., 1930) are irritant to the lung. Under field conditions the combustion products of materials such as some solvents (Conner et al., 1962) or polyurethane plastics produce marked pulmonary irritation. Other usually harmless materials such as building materials (Dufore, 1963) and wood (Olsen et al., 1933; Henser, 1944; Zikria, 1972a, b) may release pulmonary irritants depending on the conditions of their combustion. Sidor and Peters (1974) reported an excess of chronic nonspecific respiratory disease in Boston firefighters, while serial tests of pulmonary function demon-

*Supported by research grant $\mathrm{OH} 00369$ from the National Institute of Occupational Safety and Health and NIEHS Center Grant ES-0000-2.

†Recipient of a Clinical Sciences Fellowship (Epidemiology) from the National Health and Medical Research Council of Australia.

Received for publication 5 December 1977 Accepted for publication 1 June 1978 strated an abnormally rapid regression with time (Peters et al., 1974). It is not known whether these changes are a result of occasional acute episodes of inhalation of high concentrations of irritant smoke or are the cumulative effect of frequent exposure to low concentrations.

The purpose of this investigation was to determine the extent to which acute changes in pulmonary function occur during routine firefighting duty and to relate any changes to symptoms and to indices of smoke exposure.

\section{Methods}

The investigation was conducted in a moderately busy fire station housing an engine and a ladder company, each with a complement of four or five men for each of four work shifts in a mixed residential, retail and light industrial area of the city of Boston. Over a six-week period our research team remained at the fire station to acquire data on a total of 39 participants of mean age 37.9 years (range 25-56 yr).

After every fire a questionnaire was completed which sought information on the type of fire, the estimated severity and duration of smoke exposure, the time since exposure and the use of respiratory protective devices. The occurrence of symptoms (sore throat, dyspnoea, chest tightness, wheeze, nasal discharge, cough, sputum production, nausea, headache, dizziness, palpitations, muscle pain) 
during the fire, and persisting until the time of examination, was also obtained from the questionnaire. The presence of chronic respiratory symptoms was ascertained using a standard questionnaire (Sidor and Peters, 1974) and smoking history was analysed to obtain current smoking habit. There were 22 current smokers and 17 non-smokers (including 8 ex-smokers).

Pulmonary function and expired carbon monoxide concentration were measured at the beginning of each work shift and upon return of the firefighters to their quarters following any incident. Three technically satisfactory forced vital capacity manoeuvres were performed on a Stead-Wells spirometer (Wells et al., 1959). The spirograms were measured for forced expiratory volume in one second $\left(F E V_{1} \cdot 0\right)$. The mean of the three values obtained was corrected to BTPS before analysis. Each subject served as his own control. Reduction in $F_{E V} \cdot 0\left(\triangle F E V_{1 \cdot 0}\right)$ for each participant was measured by subtracting the $\mathrm{FEV}_{1.0}$ obtained after each fire from the baseline $F_{E V_{1} .0}$ measured at the beginning of the work shift. Predicted values of FEV 1.0 by age and sex were obtained from Kory et al. (1961).

Alveolar gas was collected using a bag with a Rudolph valve, and carbon monoxide concentration was measured with an Ecolyzer (Bay et al., 1972) from which carboxyhaemoglobin levels were estimated (Stewart, 1975).

Samples of the smoke encountered in the fires were collected by a specially designed apparatus mounted in a firefighter's uniform (Gold et al., 1978). The firefighter turned on the sampling device on entering the fire area and turned it off when leaving the area; a timer monitored the duration of sampling. The collected samples were analysed for $\mathrm{HCl}, \mathrm{HCN}, \mathrm{NO}_{2}$ and $\mathrm{CO}$. Particulate matter was collected on a glass-fibre filter to estimate gravimetrically the concentration of total suspended particulates.

The data were analysed on the Harvard-MIT IBM 360 computer using statistical procedures from the DATA TEXT SYSTEM (Armor and Couch, 1972). The emphasis in the analysis was on the first fire of a work shift because for second and subsequent fires there was no certain measurement of the baseline value of $\mathrm{FEV}_{1.0}$ with which to compare a subsequent value.

Information was collected from 39 subjects covering 137 fire attendances. The distribution of the number of observations for each subject is presented in Table 1. While some individuals were measured more frequently than others, there was no evidence that the data were biased by abnormal sensitivity of any individual subject.
Table 1 Distribution of 137 observations by subject. (First fire only)

\begin{tabular}{cc}
\hline $\begin{array}{l}\text { Numbers of fires for which } \\
\triangle F E V_{1.0} \text { available }\end{array}$ & Number of subjects \\
\hline 1 & 9 \\
2 & 6 \\
3 & 4 \\
4 & 8 \\
5 & 6 \\
6 & 4 \\
7 & 0 \\
8 & 1 \\
10 & 1 \\
Total 137 & 39 \\
\hline
\end{tabular}

\section{Results}

During the period of the investigation nearly half the runs attended by the firefighters were false alarms which did not involve any exposure to smoke. In addition, at each fire at least one firefighter was assigned to work in a situation where he was not exposed to smoke (for example, the pump operator on an engine company). No change in $\mathrm{FEV}_{1.0}$ occurred from 56 observations where there was no exposure to smoke (mean $\triangle F V_{1.0} \pm$ standard deviation (SD) $=0.00 \pm 0.13$ litre $)$.

The median time between cessation of exposure to smoke and the performance of pulmonary function tests was 29.0 minutes. The distribution of $\triangle F E V_{1.0}$ during first fires is shown in the Figure. On 41 occasions the first fire of the work shift was associated with a decrease in $\mathrm{FEV}_{1.0}$ of more than 0.10 litre (i.e. $30 \%$ of the observations on first fires). The largest decline observed during the study was 1.4 litre observed during a second fire in a subject exposed to burning silicone plastic and butyl rubber insulation material (Smith et al., 1978).

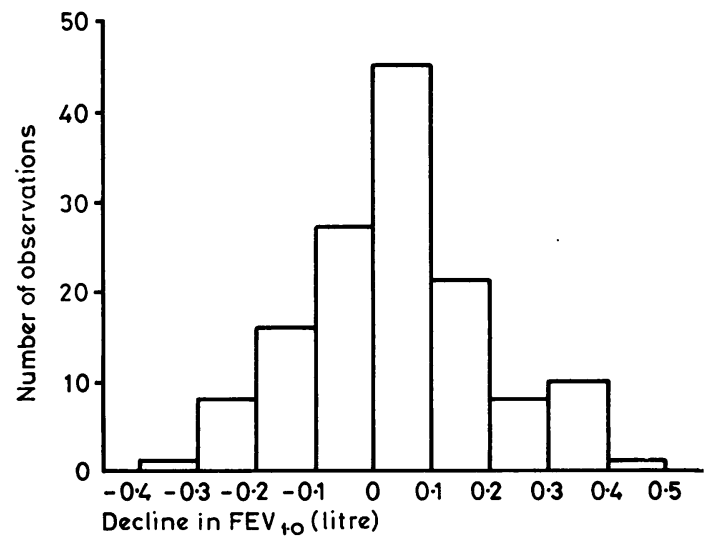

Figure Frequency distribution of decline in FEV 1.0 (litre) at first fire of work shift (137 observations). 
Changes in FEV 1.0 during the first fire of a tour of duty were examined for their relationship to severity and duration of exposure to smoke (Table 2). Analysis of variance showed that $\triangle F E V_{1.0}$ was related to the firefighter's assessment of the severity of his exposure $(\mathrm{P}<0.01)$ but not to his assessment of duration of exposure $(P=0 \cdot 12)$.

Table 2 Decline in FEV $V_{1.0}$ classified by firefighters' assessment of severity and duration of exposure at first fire*

\begin{tabular}{|c|c|c|c|}
\hline \multirow[t]{2}{*}{ Duration of exposure } & \multicolumn{3}{|c|}{ Severity of exposure } \\
\hline & Light & Moderate & Heavy \\
\hline$<10$ minutes & $\begin{array}{l}0.02 \\
(41)\end{array}$ & $\begin{array}{l}0.05 \\
(31)\end{array}$ & $\begin{array}{l}0 \cdot 14 \\
(10)\end{array}$ \\
\hline 11-15 minutes & $\begin{array}{c}-0.04 \\
\text { (5) }\end{array}$ & $\begin{array}{r}0.09 \\
(9)\end{array}$ & $\begin{array}{r}0.04 \\
(7)\end{array}$ \\
\hline 16-20 minutes & $\begin{array}{c}-0 \cdot 10 \\
(6)\end{array}$ & $\begin{array}{r}0.01 \\
(3)\end{array}$ & $\begin{array}{c}0.08 \\
(4)\end{array}$ \\
\hline$>20$ minutes & $\begin{array}{l}0.01 \\
(4)\end{array}$ & $\begin{array}{r}0 \cdot 19 \\
(3)\end{array}$ & $\begin{array}{c}0 \cdot 13 \\
(5)\end{array}$ \\
\hline $\begin{array}{l}\text { Column marginal } \\
\text { (weighted means) }\end{array}$ & $\begin{array}{l}-0.03 \\
(56)\end{array}$ & $\begin{array}{l}0.09 \\
(46)\end{array}$ & $\begin{array}{l}0 \cdot 10 \\
(26)\end{array}$ \\
\hline
\end{tabular}

* Mean $\triangle F E V_{1.0}$ in litres (number of firefighters).

Duration of exposure omitted on 9 occasions.

A significant association was found between $\triangle F E V_{1.0}$ during the first fire of a work shift and cough, or eye irritation (Table 3). These findings suggest a predictive value of these particular symptoms for reduction in pulmonary function. Respiratory symptoms were also reported more frequently during fires where the smoke exposure was considered to be heavy than during fires with moderate or light smoke exposure (Table 4).

Table 3 Decline in FEV $V_{1.0}$ classified by presence or absence of symptoms during first fire

\begin{tabular}{llll}
\hline Symptom & $\begin{array}{l}\text { Symptom present } \\
\text { Mean } \pm S D \\
\text { litres } \\
\text { (Number } \\
\text { of subjects) }\end{array}$ & $\begin{array}{l}\text { Symptoms absent } \\
\text { Mean } \pm S D \\
\text { litres } \\
\text { (Number } \\
\text { of subjects) }\end{array}$ & $\begin{array}{l}\text { Probability from } \\
\text { test }\end{array}$ \\
\hline Cough & $\begin{array}{l}0.09 \pm 0.17 \\
(41)\end{array}$ & $\begin{array}{l}0.02 \pm 0.14 \\
(96)\end{array}$ & 0.02 \\
Eye irritation $\begin{array}{l}0.07 \\
(61)\end{array}$ & $\begin{array}{l}0.02 \pm 0.16 \\
(76)\end{array}$ & 0.05 \\
Phlegm & $\begin{array}{l}0.08 \pm 0.15 \\
(44)\end{array}$ & $\begin{array}{l}0.03 \\
(93)\end{array}$ & \\
\hline
\end{tabular}

The concentrations of total suspended particulate matter measured during fires showed wide variation but were found to correlate with the firefighters' subjective assessment of the severity of smoke exposure: the geometric mean particulate levels were $6.9 \mathrm{mg} / \mathrm{m}^{3}$ for light exposure, $34.7 \mathrm{mg} / \mathrm{m}^{3}$ for moderate exposure and $56.1 \mathrm{mg} / \mathrm{m}^{3}$ for heavy exposure.
Table 4 Percentage of firefighters reporting symptoms classified by their estimates of severity of smoke exposure at first fire*

\begin{tabular}{lcll}
\hline Symptom & $\begin{array}{l}\text { Light } \\
\text { exposure }\end{array}$ & $\begin{array}{l}\text { Moderate } \\
\text { exposure }\end{array}$ & $\begin{array}{l}\text { Heavy } \\
\text { exposure }\end{array}$ \\
\hline Cough & 3 & 43 & 71 \\
Phlegm & 3 & 43 & 71 \\
Eye irritation & 18 & 60 & 68 \\
Nasal discharge & 5 & 39 & 55 \\
Sore throat & 2 & 6 & 30 \\
Headache & 2 & 6 & 25 \\
Dyspnoea & 0 & 2 & 25 \\
Nausea & 0 & 6 & 18 \\
Wheeze & 0 & 7 & 14 \\
Dizziness & 0 & 2 & 14 \\
Chest tightness & 0 & 2 & 11 \\
Chest pain & 0 & 4 & 7 \\
\hline
\end{tabular}

*137 observations.

Similarly, carbon monoxide concentrations in exhaled breath samples tended to be related to the subjective assessment of severity of smoke exposure. Further, when $\triangle F E V_{1.0}$ was examined by category of total particulate exposure, a clear trend was present for increasing loss of ventilatory capacity with increasing exposure (Table 5). Too few samples collected with the sampling uniform contained $\mathrm{HCl}, \mathrm{HCN}$, or $\mathrm{NO}_{2}$ to establish whether the presence of these constitutents bore a relationship to $\triangle \mathrm{FEV}_{1.0}$.

Table 5 Measured total particulate concentration and decline in $F E V_{1.0}$ at first fire

\begin{tabular}{ll}
\hline Total particulates $\left(\mathrm{mg} / \mathrm{m}^{3}\right)$ & $\triangle F E V_{1 \cdot 0} \pm S D(n)$ \\
\hline$<20$ & $0.01 \pm 0.15(20)$ \\
$20-80$ & $0.07 \pm 0.15(25)$ \\
$>80$ & $0.15 \pm 0.15(7)$ \\
\hline
\end{tabular}

Use of a protective respirator (self-contained breathing apparatus operated in the demand mode) was associated with large decreases in $\mathrm{FEV}_{\mathbf{1 . 0}}$. On the five occasions that respirators were used at first fires the mean $\triangle F^{2} V_{1.0}$ was 0.21 litre, which suggests either that the equipment was put on after significant exposure to irritant smoke had occurred, that it was removed before it was safe to do so, or that it leaked.

The mean baseline value of $\mathrm{FEV}_{1.0}$ of current smokers $(3.69$ litre $=94.3 \%$ predicted $)$ was similar to that of current non-smokers and ex-smokers ( 3.66 litre $=98.9 \%$ predicted). Current non-smokers showed a tendency to a greater mean decline in $F V_{1.0}$ on exposure to heavy or moderate smoke than smokers (mean $\triangle F E_{1.0} \pm$ SD for non-smokers was $0.08 \pm 0.13$ litre, $\mathrm{n}=39$, and for smokers was $0.03 \pm 0.16$ litre, $n=98),(P=0 \cdot 1)$. There was no 
association between cigarette smoking category and smoke exposure, and the increase in $\triangle F E V_{1.0}$ with increasing severity of exposure was present both for current smokers and for current non-smokers.

The average decline in $\mathrm{FEV}_{1.0}$ as a result of fighting a fire during the day shift (mean $\triangle F E_{1.0}$ $\pm \mathrm{SD}=0.02 \pm 0.15$ litre, $\mathrm{n}=65$ ) tended to be less than during the night shift $(0.07 \pm 0.15$ litre, $n=72)$ but within each work shift the relationship between severity of fires and $\triangle F E V_{1.0}$ persisted. Analysis of variance indicated that the relationship between smoke exposure and $\triangle F E V_{1.0}$ was not significantly related to duration of exposure, work shift, or smoking category. There was no separate relationship between decline in $\mathrm{FEV}_{1.0}$ and pre-existing respiratory symptoms (chronic cough and sputum, exertional dyspnoea). However, only three subjects admitted to chronic bronchitis (Sidor and Peters, 1974) and only eight to shortness of breath when hurrying or walking up a hill. No subject gave a history of current asthma, and only one subject admitted to a past history of asthma. He contributed only one observation in which he experienced light exposure to smoke. His initial FEV 1.0 was 4.00 litre and FEV 1.0 measured $8 \mathrm{~min}$ after exposure was 3.99 litre.

The initial level of $\mathrm{CO}$ in alveolar gas in current non-smokers was (mean \pm SD) $6 \cdot 1 \pm 4.0 \mathrm{ppm}$, and in current smokers $14 \cdot 7 \pm 12 \cdot 1 \mathrm{ppm}$, indicating a carboxyhaemoglobin level of about $2 \%$ in the blood of smokers. Small but significant increases in CO content of alveolar gas were related to the severity of exposure to smoke. When exposure was heavy, the mean rise in concentration of $\mathrm{CO}$ in alveolar gas was $3 \mathrm{ppm}$ in smokers and $4 \mathrm{ppm}$ in non-smokers.

We concentrated our analysis on the first fire of each work shift because the effect of a second fire on respiratory function may be influenced by a previous fire. The influence of second and third fires was examined separately but any conclusion concerning them must allow for the difficulty of deciding on an appropriate initial value from which to estimate $\triangle F E V_{1.0}$. We estimated all declines from the initial value for each work shift so that, in the absence of a delayed effect of a first fire, the decrease that may be attributed to a second fire was obtained by subtracting the decrease associated with the first fire from the reduction associated with both fires. When estimated in this way the decline associated with a second fire tended to be greater than that associated with the preceding fire. The third fire of a work shift did not cause any further loss of ventilatory capacity. There was, however, a significant relationship between severity of smoke exposure and $\triangle F E V_{1.0}$ for both second and third fires (Table 6).

Because of practical considerations it was not possible to design the investigation to look specifically at delayed effects of smoke exposure on respiratory function. However, indirect evidence of persistent effects was seen when the decline in $\mathrm{FEV}_{1.0}$ was examined for a second fire at which smoke exposure was classified as light. If the previous exposure at the first fire was heavy, the estimated decrease in $\mathrm{FEV}_{1.0}$ at the second fire (mean $\triangle F V_{1.0} \pm S D=0.17 \pm 0.15$ litre, $\left.n=5\right)$ tended to be greater than if the exposure at the first fire was light $(0.04 \pm 0.19$ litre, $n=5)$. This difference did not reach conventional levels of statistical significance $(P=0 \cdot 10)$.

\section{Discussion}

Although none of the fires monitored during this study caused any of the firefighters to seek medical attention for smoke inhalation, acute changes in pulmonary function measured by $\mathrm{FEV}_{1.0}$ were a regular occurrence. We observed a decline in $\mathrm{FEV}_{\mathbf{1 . 0}}$ of 0.10 litre or more in $30 \%$ of fire attendances. The observations suggest that the alterations in pulmonary function were more than reflex responses to heavy loadings of particulate matter. Experimental subjects exposed to a high concentration of inert particulates such as coal dust (McDermott, 1962) showed only slight, transitory changes in $\mathrm{FEV}_{1.0}$; the effects of fighting fires sometimes lasted for several hours, and in one case for several days. These results suggest that some of the changes observed may have been the result of local pharmacological activity of the gases or particulates in the smoke, such as occurs with exposure to cotton dust (Gilson et al.,

Table 6 Decline in FEV $V_{1 \cdot 0}$ classified by assessment of exposure for second and third fires

\begin{tabular}{|c|c|c|c|c|}
\hline Fire & $\begin{array}{l}\text { Light exposure } \\
\text { Mean } \pm S D \\
\text { (Number of subjects) }\end{array}$ & $\begin{array}{l}\text { Moderate exposure } \\
\text { Mean } \pm S D \\
\text { (Number of subjects) }\end{array}$ & $\begin{array}{l}\text { Heavy exposure } \\
\text { Mean } \pm S D \\
\text { (Number of subjects) }\end{array}$ & $\begin{array}{l}\text { All fires } \\
\text { Mean } \pm S D \\
\text { (Number of subjects) }\end{array}$ \\
\hline Second & $\begin{array}{l}0.06 \pm 0.19 \\
(31)\end{array}$ & $\begin{array}{l}0.23 \\
(12)\end{array}$ & $\begin{array}{l}0.24 \\
(13)\end{array}$ & $\begin{array}{l}0.14 \\
(56)\end{array}$ \\
\hline Third & $\begin{array}{l}0.08 \pm 0.18 \\
(14)\end{array}$ & $\frac{-0.02}{(2)} \pm 0.01$ & $\begin{array}{l}0.19 \pm 0.08 \\
(7)\end{array}$ & $\underset{(23)}{0.11} \pm 0.16$ \\
\hline
\end{tabular}

* Measured from baseline at beginning of work shift. 
1962) or the result of chemical stimulation of irritant receptors which may be more persistent than simple mechanical stimulation (Dr Paul Richardson, personal communication).

This study shows that, as a result of his occupation, the respiratory system of the firefighter is subject to frequent episodes of acute irritation, each of which is related to the severity of his exposure to smoke; the firefighter accepts respiratory symptoms as a part of his job. We suggest that these minor episodes may produce cumulative damage manifested by an excessive yearly decline in $\mathrm{FEV}_{1.0}$ (as demonstrated by Peters et al., 1974) and by chronic mucus hypersecretion (Sidor and Peters, 1974).

The changes in FEV 1.0 that we observed were related to the concentration of smoke surrounding the firefighter whether this concentration was derived from his subjective assessment or from the measured content of particulate matter of the smoke. It is likely that if the concentration of smoke were known in advance, potentially harmful exposure could be avoided by the firefighters using protective respiratory equipment from the outset.

At the time of this study, members of the Boston Fire Department used a self-contained breathing apparatus for personal protection when smoke conditions were perceived to be dangerous. However, some substances may be irritant to the lungs without producing warning symptoms and noxious materials may be encountered unexpectedly. This study and the previous studies of pulmonary function in firefighters (Peters et al., 1974; Musk et al., 1977a, b) suggest that respiratory protection should be worn by firefighters more frequently than has been the current practice. Our studies indicate that, in the past, firefighters have been subjected to repeated acute insults to the respiratory tract and have experienced excessive and persistent loss of pulmonary function. Partially as a result of our studies, a rule requiring use of personal protective equipment during all smoke exposures has now been adopted by the Boston Fire Department.

We are grateful for the interest and co-operation of the members of the Boston Fire Department who provided us with our data, to Dr Avram Gold and Mr Peter Provost for analysis of the smoke samples, and to Drs Pekka Roto, Daniel Guyton and Jonas Kalnas for technical assistance and their help in collecting the data.

\section{References}

Armor, D. J., and Couch, A. S. (1972). Data-Text Primer: An Introduction to Computerized Social Analysis. The Free Press: New York.

Bay, H. Y., Biurton, K. D., Lieb, H. C., and Oswin, H. G. (1972). Electrochemical measurement of carbon monoxide. American Laboratory, 4, 57-58.
Conner, E. H., Dubois, A. B., and Comroe, J. H. (1962). Acute chemical injury to the respiratory tract and lungs. Anaesthesiology, 23, 538-547.

Dufore, R. E. (1963). Survey of available information on the toxicity of the combustion and thermal decomposition products of certain building materials under fire conditions. Underwriters' Laboratories Bulletin of Research, No. 53.

Gilson, J. C., Stott, H., Hopwood, B. E. C., Roach, S. A., McKerrow, C. B., and Schilling, R. S. F. (1962). Byssinosis: the acute effect on ventilatory capacity of dusts in cotton ginneries, cotton, sisal and jute mills. British Journal of Industrial Medicine, 19, 9-18.

Gold, A., Burgess, W. A., and Clougherty, E. V. (1978). Exposure of firefighters to toxic air contaminants. American Industrial Hygiene Association Journal, 39, 534-539.

Gross, D., Loftus, J. J., Lee, T. G., and Gray, V. E. (1969). Smoke and Gases Produced by Burning Aircraft Interior Materials. United States Department of Commerce, National Bureau of Standards, Building Science Series 18.

Henser, E. (1944). Cellulose Chemistry, p. 545. John Wiley and Sons: New York.

Kory, R. C., Callahan, R., Boren, H. G., and Syner, J. C. (1961). The Veterans' Administration Army cooperative study of pulmonary function. I. Clinical spirometry in normal men. American Journal of Medicine, 30, 243-249.

McDermott, M. (1962). Acute respiratory effects of coal dust particles. Journal of Physiology, 162, 53.

Musk, A. W., Peters, J. M., and Wegman, D. H. (1977a). Lung function in firefighters. I: A three year follow up of active subjects. American Journal of Public Health, 67, 626-629.

Musk, A. W., Peters, J. M., and Wegman, D. H. (1977b). Lung function in firefighters. II: A five year follow up of retired subjects. American Journal of Public Health, 67, 626-629.

Nichols, B. H. (1930). The clinical effects of inhalation of nitrogen dioxide. American Journal of Roentgenology, 23, 516-520.

Olsen, J. D., Brunjes, A. S., and Sabetta, V. S. (1930). Gases produced by the decomposition of nitrocellulose and cellulose acetate photographic films. Industrial Engineering and Chemistry, 22, 860-866.

Olsen, J. D., Ferguson, G. E., and Scheflan, L. (1933). Gases from thermal decomposition of common combustible materials. Industrial Engineering and Chemistry, 25, 599-603.

Peters, J. M., Theriault, G. P., Fine, L. J., and Wegman, D. H. (1974). Chronic effect of firefighting on pulmonary function. New England Journal of Medicine, 291, 1320-1322.

Sidor, R., and Peters, J. M. (1974). Prevalence rates of chronic non-specific respiratory disease in firefighters. American Review of Respiratory Disease, 109, 255-261.

Smith, T. J., Musk, A. W., Gold, A., and Roto, P. (1978). Acute respiratory effects of a fire involving silicone rubber. International Archives of Occupational and Environmental Health, 41, 139-145.

Stewart, R. D. (1975). The effect of CO on humans. Annual Review of Pharmacology, 15, 409-432.

Thomas, D. M. (1971). The smoke inhalation problem. In Proceedings of a Symposium on Occupational Health and Hazards of the Fire Service, Notre Dame University, South Bend, Indiana, pp. 21-27. International Association of Firefighters: Washington DC.

Wells, H. S., Stead, W. W., Rossing, T. D., and Oganovich, J. (1959). Accuracy of an improved spirometer for recording fast breathing. Journal of Applied Physiology, 14, 451-459.

Zikria, B. A., Ferrer, J. M., and Floch, H. D. (1972a). The chemical factors contributing to pulmonary damage in 
smoke poisoning. Surgery, 71, 704-709.

(1972b). Smoke and carbon monoxide poisoning in fire Zikria, B. A., Weston, G. C., Chodoll, M., and Ferrer, J. M. victims. Journal of Trauma, 12, 641-645. 